\title{
Tissue Infiltration in a CD8 Lymphocytosis Syndrome Associated with Human Immunodeficiency Virus-1 Infection Has the Phenotypic Appearance of an Antigenically Driven Response
}

\author{
S. Itescu, J. Dalton, H.-Z. Zhang, and R. Winchester \\ Division of Autoimmune and Molecular Diseases, Department of Pediatrics, Columbia University, \\ College of Physicians and Surgeons, New York 10032
}

\begin{abstract}
HIV-1 infection may initiate to an HLA-associated response designated diffuse infiltrative lymphocytosis syndrome, characterized by increased numbers of circulating $\mathrm{CD8} T$ cells that infiltrate salivary glands, lungs, gastrointestinal tract, and kidneys. Since this response could either be an antigenically driven process induced by HIV-1 or a lymphoproliferation of cells with neoplastic or unusual features, we sought to define the phenotype of the cellular populations, the nature of tissue derangement, and the tissue localization of virus in diffuse infiltrative lymphocytosis syndrome. Circulating CD8 $\mathrm{T}$ cells were greatly increased while CD4 T cell numbers remained in the range found in asymptomatic seropositive persons. The majority of CD8 and CD4 $\mathrm{T}$ cells in both blood and tissues had the memory phenotype of $\mathrm{CD}^{+}{ }^{+}\left(\beta_{1}\right.$ integrin) and $\mathrm{CD11a}^{+} /$ CD18 ( $\beta_{2}$ integrin) expression, but lacked markers of recent activation. A proportion of the circulating CD8 T cells also expressed CD57 ( Leu 7) but not other markers of natural killer cells. HIV-encoded proteins were identified in tissue macrophages located in periacinar areas of the salivary glands. CD54 (intercellular adhesion molecule-1), a ligand for the CD11a integrin, was strongly expressed on postcapillary venule endothelium within lymphoid foci, and HLA-DR molecules were found on limited regions of ductular epithelium adjacent to lymphoid aggregates. These findings suggest that $(a)$ the visceral lymphocytic infiltration in diffuse infiltrative lymphocytosis syndrome is an antigen-driven, and MHC-determined, host immune response to an element associated with HIV-1 infection, and $(b)$ that the specific adhesive molecule interactions mediating the cellular influx, as well as the subsequent tissue damage, reflect altered patterns of gene expression in tissues undergoing an immune response. (J. Clin. Invest. 1993. 91:2216-2225.) Key words: diffuse infiltrative lymphocytosis syndrome • CD8 $T$ cells $\bullet$ tissue infiltration $\bullet$ antigen driven $\bullet$ adhesion molecules
\end{abstract}

\section{Introduction}

Progressive CD4 $\mathrm{T}$ cell depletion and incapacitation occurring at various rates in different persons are hallmarks of infection

Address correspondence to Silviu Itescu, M.D., Columbia University, College of Physicians and Surgeons, Department of Pediatrics, $630 \mathrm{~W}$. 168th Street, BHS 116, New York, NY 10032.

Received for publication 5 February 1992 and in revised form 30 November 1992.

J. Clin. Invest

(c) The American Society for Clinical Investigation, Inc. $0021-9738 / 93 / 05 / 2216 / 10 \quad \$ 2.00$

Volume 91, May 1993, 2216-2225 with HIV-1, however the mechanisms responsible for this impairment are currently not well understood (1). In contrast, T cells of the CD8 lineage are generally not infected with HIV-1 and have been implicated in both potentially protective antiHIV responses $(2,3)$ as well as in mechanisms causing the depletion of autologous CD4 T cells (4). CD8 lineage T cells are often moderately elevated early in the course of HIV-1 infection, however, in most cases, this is usually a transient phenomenon and CD8 $\mathrm{T}$ cell numbers tend to subsequently decline in parallel with CD4 T cell depletion (5).

Certain adults respond to HIV-1 infection by developing a syndrome characterized by persistent circulating CD8 lymphocytosis, and visceral lymphocytic infiltration, predominantly of the salivary glands and lungs (6). The more prominent clinical features of this diffuse infiltrative lymphocytosis syndrome (DILS) ${ }^{1}$ have some similarities to those of classic Sjögren's syndrome and include sicca symptoms, parotid enlargement that is often massive, and, in some individuals, progressive lymphocytic interstitial pneumonitis and renal infiltrative involvement that is manifest as a type IV renal tubular acidosis. Less frequently, other tissues are also infiltrated, leading to manifestations such as periportal inflammatory disease of the liver, dysmotility syndromes of the small and large intestines, and bilateral mastitis. Individuals with DILS have a low rate of progression to frank immune deficiency, with an annual rate of developing an opportunistic infection of only $0.9 \%$ (7). Moreover, most of these persons maintain relatively preserved absolute numbers of CD4 T cells, at levels of asymptomatic seropositive individuals, suggesting that their host response may in some way prevent the $\mathrm{T}$ cytopathic events characteristic of progressive HIV-1 infection. However, despite persistence of high CD4 $T$ cell numbers, individuals with DILS have a greatly increased risk of developing salivary or lacrimal gland B cell lymphoma (7).

Susceptibility to developing DILS is associated with the presence of particular MHC class II and I alleles. The increase in frequencies of the structurally related MHC class II alleles HLA-DR5 (DRB1*1102) and HLA-DR6 (DRB1*1301) (8) supports the notion of DILS being a distinct syndrome and, more importantly, an immunogenetically determined host response to HIV infection. Directing further attention to possible $\mathrm{T}$ cell recognition events in DILS that may involve CD8 $\mathrm{T}$ cells, there is also a significantly decreased frequency in this disorder of the MHC class I determinant HLA-B35, a specificity that, when present in other HIV-infected persons, has been

1. Abbreviations used in this paper: ARC, AIDS-related complex DILS, diffuse infiltrative lymphocytosis syndrome; ICAM, intercellular adhesion molecule; LFA, lymphocyte function-associated antigen; NK, natural killer; TCR, T cell receptor. 
associated with an increased rate of progression to AIDS-related opportunistic infections (7).

CD8 or CD4 lineage $\mathrm{T}$ lymphocytes recognize antigen in the context of MHC class I or II determinants, respectively (9). This interaction and its consequences (10-12), the binding of $T$ cells to and their migration across endothelial surfaces, as well as their homing to specific tissues undergoing immunemediated inflammation (13) depend on adhesive interactions between cell surface structures such as integrins and a variety of ligands including intercellular adhesion molecules (ICAMs) and extracellular matrix components $(14,15)$. Acquisition of these surface structures, for example, CD29, the $\beta$ chain common to members of the $\beta_{1}$ integrin family, the $\beta_{2}$ integrin CD1 la/CD18, and the tyrosine phosphatase CD45RO (16), is regulated in a relatively coordinated fashion (17) and leads to a permanent phenotype that distinguishes memory from naive $\mathrm{T}$ cells. This sustained phenotype contrasts with the transient expression of markers of recent activation, such as HLA-DR or interleukin-2 receptors. These memory cells demonstrate rapid anamnestic response to recall antigens $(11,16,18)$, contain cytotoxic T cell precursors (19), and are capable of enhanced $\gamma$-interferon production (17). In particular, CD8 T cells use CD11a/CD18 (lymphocyte function-associated antigen [LFA-1]) molecules to facilitate target adhesion and cytotoxicity $(11,14)$. The entry of these memory $T$ cells to specific tissues undergoing an immune response is regulated by the cytokine-mediated induction of ICAMs and other adhesion molecules on vascular endothelium (14).

In this study we sought to determine whether the circulating and infiltrative lymphocytosis occurring in DILS has the characteristics of an antigenically driven host response, where these lymphocytes would display the phenotype of memory $\mathrm{T}$ cells, possibly with evidence of recent activation. Alternatively, the lymphocytosis could reflect a nonantigenically driven process of $T$ cell lymphoproliferation or the accumulation of cells with unusual phenotypes. Moreover, since HIV-1 was the principal candidate for providing antigen stimulation, we analyzed involved tissues to determine expression and cellular localization of virally encoded gp 120 molecules.

\section{Methods}

Patients. 10 individuals with DILS were studied. All were HIV-1 positive by both ELISA and Western blot analysis. At the time of study none met criteria for AIDS, and eight met criteria for AIDS-related complex (ARC), or stage 3B (20), with fevers, generalized adenopathy, and weight loss. All patients had persistent bilateral parotid gland enlargement for $>6 \mathrm{mo}$, which was massive in seven. Lymphocytic interstitial pneumonitis was present in four, lymphocytic interstitial nephritis in two, and lymphocytic hepatitis in one, all documented by tissue biopsy. Detailed clinical data describing these patients have been previously reported (21). None had received corticosteroid or other immunosuppressive therapy before this analysis. Controls consisted of 34 individuals, 25 of whom were HIV positive ( 8 healthy asymptomatic, 8 with ARC, 9 with AIDS) and 9 who were HIV negative. After diagnostic minor salivary gland, pulmonary, or renal biopsy, four of the patients received zidovudine treatment, at dosages $100-200 \mathrm{mg}$ every 6-8 $\mathrm{h}$. This therapy caused $>50 \%$ diminution in salivary gland size in each of the four patients with DILS, as early as $5 \mathrm{~d}$ after initiating therapy.

Lymphocyte phenotypic analysis. Mononuclear cells from heparinized peripheral blood were separated by centrifugation on Ficoll-Hypaque gradients (Pharmacia LKB Biotechnology, Inc., Piscataway,
$\mathrm{NJ})$. Monoclonal antibodies OKT-11 (CD2), 89b1 (CD3), 91d6 (CD4), OKT8 (CD8), LFA-1 (CD11a), MN41 (CD11b), BW209 (CD16), SG157 (HLA-DR), and Tac (CD25) were used in immunofluorescence after conjugation with fluorescein isothiocyanate or fluorescein succinimidyl biotin as described (22). CD29, CD14 (LeuM3), and CD20 monoclonal antibodies, graciously provided by Becton Dickinson Immunocytometry Systems, Mountain View, CA, were directly conjugated with phycoerythrin, while monoclonal antibodies CD45R, CD57 (Leu7), both gifts of Becton Dickinson, and $\gamma \delta \mathrm{T}$ cell receptor (TCR), purchased from T Cell Sciences, Inc., Cambridge, MA, were directly conjugated with fluorescein isothiocyanate. Avidin conjugated with allophycoyanin or phycoerythrin was used in two or three color formats. The percentages of double- and triple-labeled lymphocytes obtained from either peripheral blood or bronchoalveolar lavage were determined by flow cytometry using an instrument equipped with argon and helium neon ion lasers, five parameter electronics, and a logarithmic amplifier (Becton Dickinson). Gating on combinations of low angle forward and 90 degree side scatter defined for each individual by CD3 and CD14 reagents enabled positive selection for lymphocytes and exclusion of monocytes in the analysis. The statistical significance of differences in the medians between groups were calculated using the Mann-Whitney two-tailed test.

Histopathologic studies. Minor salivary gland biopsies obtained from all 10 patients, pulmonary parenchymal tissue from two, and one renal biopsy specimen, were fixed, embedded in paraffin, sectioned serially, and stained with hematoxylin-eosin. Minor salivary gland biopsy specimens were graded according to the criteria of Chisholm and Mason (23). All of the tissues were stained and cultured for acidfast bacilli and fungi.

Biotin-avidin immunoperoxidase staining. Four minor salivary gland biopsies of the lower lip and one renal biopsy were placed in embedding medium (O.C.T. compound; Miles Laboratories Inc., Naperville, IL) in airtight plastic capsules, snap frozen in liquid $\mathrm{N}_{2}$, and stored at $-70^{\circ} ; 5-\mu \mathrm{m}$ sections were prepared, fixed in acetone, and stained with CD2, CD3, CD4, CD8, CD14, CD29, CD11a, CD54 (ICAM-1), and HLA-DR monoclonal antibodies, as described (24). Sections were also stained with the monoclonal antibody $91-35$ specific for HIV-1 gp120, kindly provided by Dr. F. Celada, New York University Medical Center. The mAb 91-35 does not inhibit CD4-gp1 20 binding or syncytium formation (25). Appropriate dilutions of monoclonal antibody, usually from ascites samples, or control myeloma protein were incubated with the tissue sections. After rinsing, the sections were treated with biotin-conjugated $\mathrm{F}\left(\mathrm{ab}^{\prime}\right)_{2}$ anti-mouse Ig followed by avidin-conjugated horseradish peroxidase (Vector Laboratories, Inc., Burlingame, CA ) and substrate 3'-, 3'diaminobenzidine (Sigma Chemical Co., St. Louis, MO). The slides were then counterstained with methylene blue.

\section{Results}

\section{Immunophenotypic analysis of circulating lymphocyte populations}

Enumeration of CD4 and CD8 T-cells. In two-color fluorescence experiments designed to determine the proportion of $T$ cells expressing CD4 and / or CD8 molecules, the median numbers of circulating CD8 cells were found to be significantly higher in those with DILS than in healthy HIV-positive controls, those with ARC, AIDS, or HIV-negative controls, Table I. Median CD4 T cell numbers in individuals with DILS were not different from levels seen in healthy HIV seropositive controls, but were significantly higher than in those with ARC or AIDS. Less than $1 \%$ of cells stained for both markers, data not illustrated. Other two-color experiments (not illustrated) showed that at least $90-95 \%$ of the expanded CD8 lymphocyte population in individuals with DILS expressed brightly the pan-T cell marker CD3, and $<5 \%$ stained positively for $\gamma \delta \mathrm{T}$ 
Table I. Increased Circulating CD8 Cells and Relative Preservation of CD4 Cells in Individuals with DILS

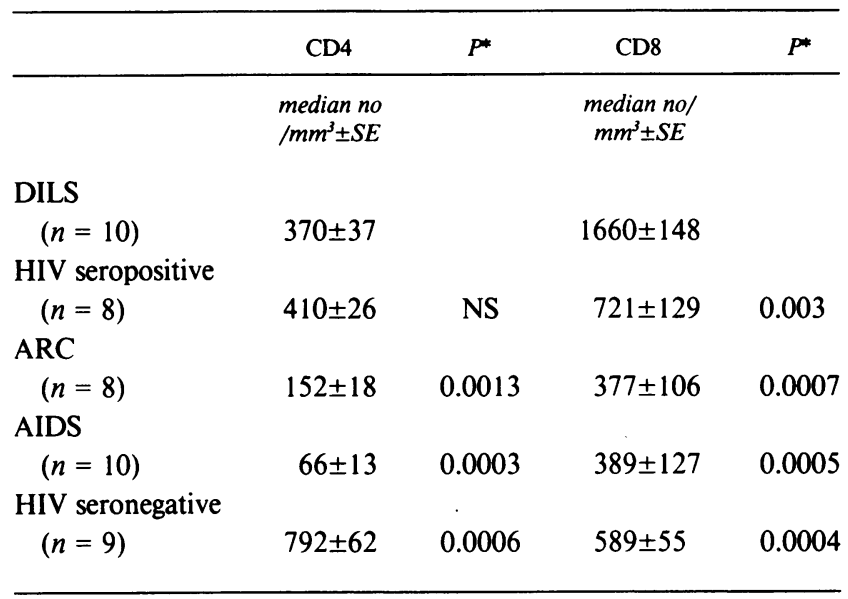

* Mann-Whitney two-tailed test comparison to individuals with DILS.

cell receptors, implying that the majority of the circulating CD 8 cells in individuals with DILS are T lymphocytes using $\alpha \beta$ receptors.

Delineation of memory phenotype. In triple-staining experiments designed to examine the surface expression of the $\beta_{1}$ integrin CD29 and the T200 leukocyte common antigen structure CD45R on circulating CD8 $\mathrm{T}$ cells, the major proportion of $\mathrm{CD}^{+}$cells in 9 out of 10 individuals with DILS cells stained moderately to very brightly with CD29 mAbs and dimly to negatively with CD45R mAbs, as shown in Fig. 1. The CD8 ${ }^{+}$ CD29 ${ }^{\text {bright }} \mathrm{CD} 45 \mathrm{R}^{-}$subset accounted for an average of $67 \%$ of the total increase in CD8 $\mathrm{T}$ cell numbers in these persons. The ratio of $\mathrm{CD} 8^{+} \mathrm{CD} 29^{\text {bright }}$ to $\mathrm{CD} 8^{+} \mathrm{CD} 45 \mathrm{R}^{\text {bright }}$ cells, as well as the total numbers of circulating $\mathrm{CD} 8^{+} \mathrm{CD} 29^{\text {bright }}$ cells, were significantly higher in those with DILS than in either HIVnegative or HIV-positive controls, Table II.

In other triple-staining experiments, the $\mathrm{CD} 8^{+} \mathrm{CD} 29^{\text {bright }}$ cells in all cases studied were shown also to express brightly the $\beta_{2}$ integrin molecule CD11a/CD18 (LFA-1), as detected by a CD1 la mAb (Table III). A subset of the expanded CD8 population among those with DILS also expressed CD57 (Leu 7) molecules, Table III. Triple staining experiments demonstrated that $41-97 \%$ of $\mathrm{CD} 8{ }^{+} \mathrm{CD} 57^{+}$cells also expressed CD29 molecules brightly (Fig. 2, inset), but not natural killer (NK)associated markers such as CD1 lb/CD18 and CD16, data not shown. In addition, these cells were of the same size and morphology as other circulating lymphocytes, suggesting that they are not large granular lymphocytes which have been reported to be $\mathrm{CD} 57^{+}$and to possess NK function (26).

No detectable increase in expression of markers of recent activation. Dual staining experiments demonstrated that, in contrast to markers of memory acquisition, the expanded CD8 lymphocyte population in DILS did not express markers of recent activation, such as MHC class II molecules, Table II, or interleukin-2 receptors, data not illustrated. Similarly, individuals with DILS had significantly lower proportions of CD4 cells expressing CD25 (interleukin-2 receptors) than asymptomatic HIV-positive controls, those with ARC, or those with AIDS, Table IV. Surface expression of HLA-DR molecules by the CD4 $\mathrm{T}$ cell population in DILS was also lower than in all other categories of HIV-infected individuals, most significantly in comparison to those with AIDS. In contrast, HLA-DR expression by $B$ cells was preserved in DILS, as evidenced by the $\mathrm{CD}^{-}{ }^{-} \mathrm{DR}^{+}$population in Fig. 3. Indeed, the total numbers of circulating $\mathrm{B}$ lymphocytes, defined by CD20 expression, did not differ between individuals with DILS and normal controls, data not shown.
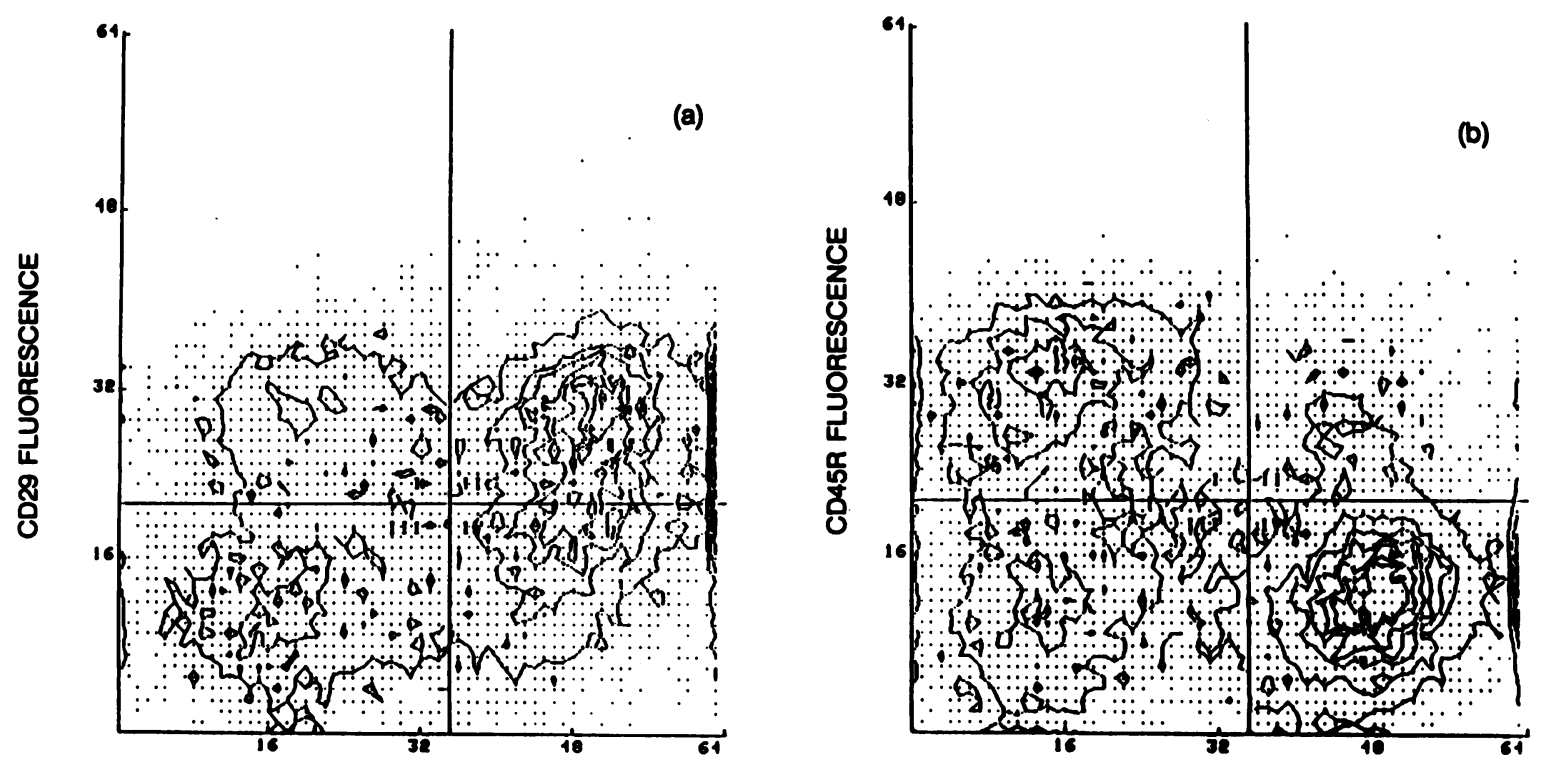

\section{CD8 FLUORESCENCE}

Figure 1. Three-color immunofluorescence analysis of circulating lymphocytes from an individual with DILS stained with phycoerythrin-, fluorescein-, or biotin-conjugated CD29, CD45R, and CD8 monoclonal antibodies, respectively, illustrating a predominance of CD8 T cells with a memory phenotype. While $59 \%$ of the CD8-positive cells expressed CD29 molecules $(a)$, only $11 \%$ expressed CD45R molecules $(b)$. 
Table II. The Expanded CD8 Population in those with DILS Has a Preponderant Phenotype of $29^{\text {bright }} 45^{-}$ but Does Not Express Markers of Recent Activation such as HLA-DR Molecules

\begin{tabular}{|c|c|c|c|c|c|c|}
\hline & $\mathrm{CD} 8^{+} \mathrm{CD} 29^{\text {bright }}$ & $P^{*}$ & $\mathrm{CD} 8^{+} \mathrm{CD} 45 \mathrm{R}^{\text {bright }}$ & $P^{*}$ & CD29:CD45R & $\mathrm{CD} 8^{+} \mathrm{DR}^{+}$ \\
\hline & median no/mm ${ }^{3} \pm S E(\%)$ & & median no/mm ${ }^{3} \pm S E(\%)$ & & & median $\% \pm S E$ \\
\hline \multicolumn{7}{|l|}{ DILS } \\
\hline$(n=10)$ & $903 \pm 85(54)$ & & $408 \pm 57(25)$ & & 1.94 & $7 \pm 1$ \\
\hline \multicolumn{7}{|l|}{$\mathrm{HIV}^{+}$} \\
\hline$(n=8)$ & $344 \pm 61(45)$ & 0.004 & $363 \pm 57(50)$ & NS & 0.92 & $8 \pm 6$ \\
\hline \multicolumn{7}{|l|}{$\mathrm{ARC}$} \\
\hline$(n=8)$ & $175 \pm 42(39)$ & 0.0007 & $149 \pm 51(40)$ & 0.0083 & 0.97 & $16 \pm 4$ \\
\hline \multicolumn{7}{|l|}{ AIDS } \\
\hline$(n=10)$ & $195 \pm 48(50)$ & 0.0004 & $120 \pm 84(31)$ & 0.014 & 1.46 & $15 \pm 4$ \\
\hline \multicolumn{7}{|l|}{$\mathrm{HIV}^{-}$} \\
\hline$(n=9)$ & $322 \pm 42(55)$ & 0.007 & $327 \pm 40(56)$ & NS & 0.93 & $7 \pm 1$ \\
\hline
\end{tabular}

* Mann-Whitney two-tailed test comparison of all numbers to individuals with DILS. ( ) Values in parentheses are percentages of gated lymphocytes.

\section{Immunohistologic studies}

Tissue morphology. Histological examination demonstrated each of the minor salivary gland biopsy samples to have two or more discrete foci of at least 50 lymphocytes per $4 \mathrm{~mm}^{2}$ of tissue, or grade 4 according to the Chisholm and Mason criteria for diagnosis of Sjögren's syndrome (23). The infiltrating mononuclear cells were pleomorphic in size and shape and did not have any morphologic characteristics of neoplastic lymphoproliferation. In most individuals, the integrity of parenchymal structures remained relatively preserved despite dense periacinar and perivascular focal infiltrates. However, the degree of salivary gland destruction tended to reflect the duration of lymphocytic infiltration, and ranged from complete preservation of glandular architecture to atrophic duct epithelium, canal dilatation, and interstitial fibrosis. Pulmonary parenchymal tissue from patients with lung involvement revealed both focal lymphoid aggregates and diffuse interstitial lymphocytic infiltration. Renal tissue from the two patients with progressive

Table III. The Expanded CD8 Population in those with DILS Primarily Expresses CD11a/CD18(LFA-1) and a Subset Expresses CD57 (LEU7)

\begin{tabular}{|c|c|c|c|c|}
\hline & $\mathrm{CD} 8{ }^{+} \mathrm{CD} 11 \mathrm{a} / \mathrm{CD} 18+$ & $P^{*}$ & $\mathrm{CD} 8{ }^{+} \mathrm{CD} 57^{+}$ & $P^{*}$ \\
\hline & $\begin{array}{l}n o / m^{3}(\%) \\
\text { median } \pm S E\end{array}$ & & $\begin{array}{l}n o / m^{3}(\%) \\
m e d i a n \pm S E\end{array}$ & \\
\hline \multicolumn{5}{|l|}{ DILS } \\
\hline \multicolumn{5}{|l|}{$\mathrm{HIV}^{+}$} \\
\hline$(n=8)$ & $481 \pm 92(66)$ & 0.042 & $187 \pm 77(26)$ & NS \\
\hline $\begin{array}{l}\text { ARC } \\
\quad(n=8)\end{array}$ & \multicolumn{3}{|c|}{ ARC } & 0.003 \\
\hline \multicolumn{5}{|l|}{ AIDS } \\
\hline$(n=10)$ & $237 \pm 157(61)$ & 0.005 & $127 \pm 46(33)$ & 0.010 \\
\hline \multicolumn{5}{|l|}{$\mathrm{HIV}^{-}$} \\
\hline$(n=9)$ & $273 \pm 71(46)$ & 0.002 & $116 \pm 31(20)$ & 0.005 \\
\hline
\end{tabular}

* Mann-Whitney two-tailed test comparison to individuals with DILS. renal insufficiency and type IV renal tubular acidosis revealed interstitial and tubular lymphocytic infiltration without any glomerular involvement.

Lineage of cells infiltrating salivary gland tissue. Lymphocytes accounted for $80-90 \%$ of the mononuclear cells infiltrating salivary tissues, while cells of the monocyte/macrophage lineage, defined by staining with a CD14 mAb, accounted for $10-20 \%$. Of the lymphocytes infiltrating the salivary tissues in each of five samples, 80-90\% expressed the pan- $\mathrm{T}$ cell markers CD2 and CD3, and, in three of three samples, $10-20 \%$ of lymphocytes, scattered within the foci, expressed the B cell marker CD20. The predominant population of infiltrating lymphocytes was CD8 positive, accounting for $60-80 \%$ of all lymphocytes. $10-15 \%$ of the lymphocytes were CD4 positive, as were most of the monocyte/macrophage lineage cells which could be differentiated by their abundance of cytoplasm, characteristic periacinar location, and CD14 expression in consecutive sections. The CD8-positive cells were usually distributed diffusely throughout salivary tissue, within lymphoid aggregates, and surrounding and infiltrating acini. In contrast, the smaller numbers of CD4-positive $T$ cells were primarily located within lymphoid foci.

Memory phenotype of infiltrating lymphocytes. From 75$90 \%$ of the infiltrating lymphocytes stained strongly positive with CD29 (not illustrated) and CD11a mAbs (Fig. $4 A$ ). These molecules were expressed most brightly on cells surrounding postcapillary venules and salivary gland acini, while lymphocytes intermediate in location between these sites stained either less intensely or negatively. In four of four biopsy specimens studied, as illustrated in fig. $4 \mathrm{~B}$, CD54 (ICAM-1) expression was observed on endothelial cells of postcapillary venules within lymphoid aggregates, but not in vessels of uninvolved salivary tissue. While this molecule was also strongly expressed by the periacinar monocyte/macrophage lineage cells, CD54 expression was entirely absent on salivary ducts and acini. Staining with mAbs specific for HLA-DR, Fig. $4 C$, revealed acini that were DR positive within and adjacent to lymphoid foci, but not at distances away from these aggregates. A small proportion of the lymphocytes within the foci were DR positive, and these were accounted for numerically by CD20-positive B cells in consecutive sections. 


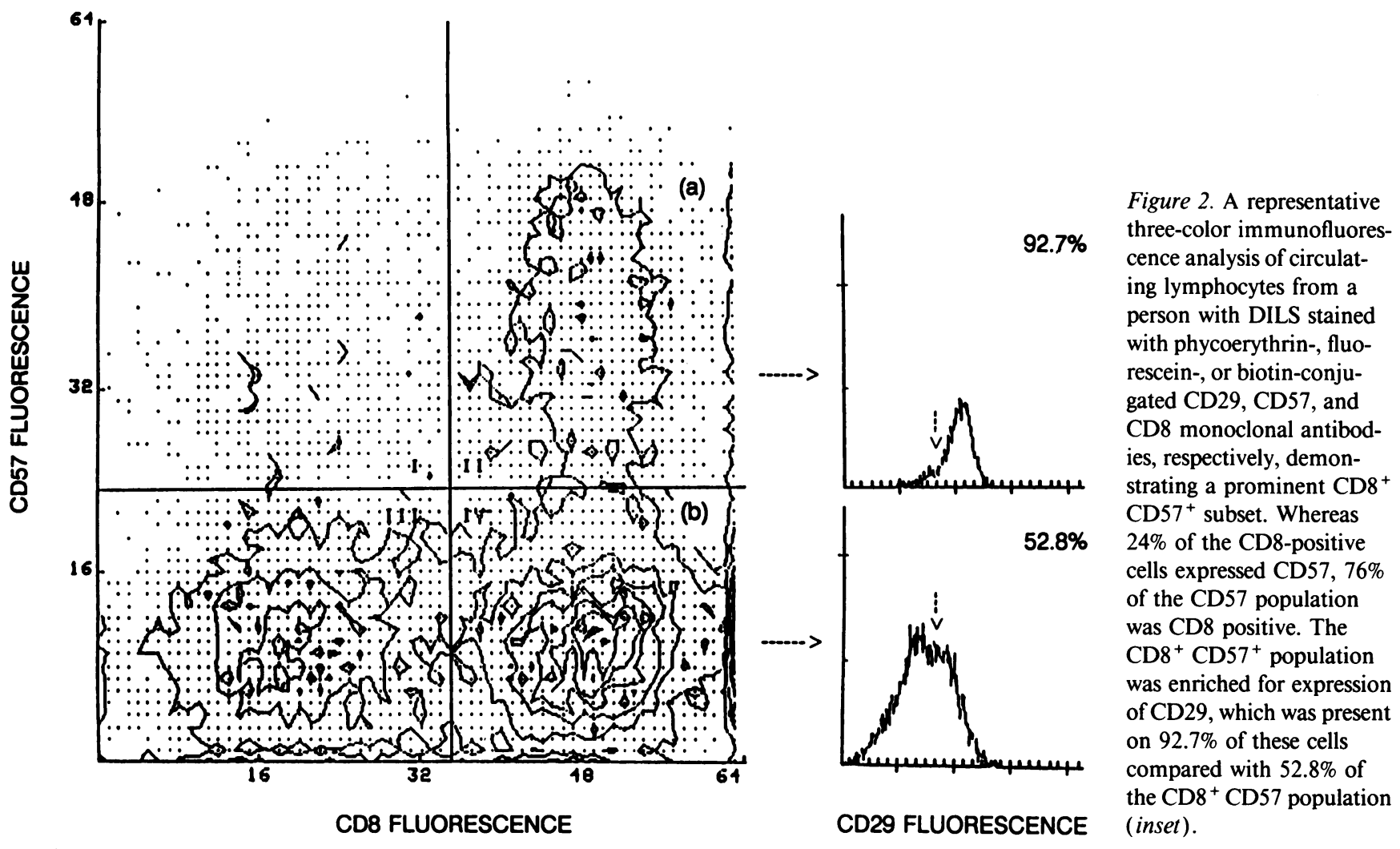

HIV-1 gp120 antigens localized to salivary gland macrophages. The cells which stained positively with CD14 mAbs, and morphologically appeared to be of monocyte / macrophage lineage, were located in periacinar and perivascular areas, as well as adjacent to lymphoid foci, and strongly expressed HLADR molecules (Fig. $4 C$ ). In consecutive sections, in three of three cases studied, from 5 to $10 \%$ of these monocyte lineage cells demonstrated positive cytoplasmic and cell-surface staining with mAbs specific for HIV-1 gp120 (Fig. 4 D). HIV-1-related antigens were more frequently observed within periacinar monocyte lineage cells at sites distant from lymphoid aggregates. Scanning multiple sections in each tissue sample studied, expression of HIV-1 proteins was very rarely observed in occasional lymphocytes, and no positive staining of acini, ducts, or venules was demonstrable with the gp $120 \mathrm{mAb}$.

Characterization of cellular infiltration in other tissues. Immunohistologic analysis of renal tissue from one individual with interstitial nephritis demonstrated that $>90 \%$ of the lymphocytes in the interstitium, primarily surrounding and infiltrating the renal tubules, expressed CD2 and CD3 pan-T cell markers. Over $70 \%$ of these cells were $\mathrm{CD} 8^{+}$and $20 \%$ were $\mathrm{CD}^{+}$. More than $75 \%$ of the lymphocytes were strongly stained by CD29 and CD11a reagents, while the glomerular endothelium, but not the tubules, expressed CD54 (ICAM-1).

Table IV. The CD4 Population in those with DILS Has Memory Phenotype but Does Not Express Markers of Recent Activation

\begin{tabular}{|c|c|c|c|c|c|c|}
\hline & CD4 & CD29:CD45R & $\mathrm{CD}^{+}{ }^{+} \mathrm{CD} 25^{+}$ & $P^{*}$ & $\mathrm{CD}^{+} \mathrm{DR}^{+}$ & $P^{*}$ \\
\hline & $\begin{array}{c}n o / m m^{3} \\
m m^{3} \pm S E\end{array}$ & median $\pm S E$ & median $\% \pm S E$ & & median $\% \pm S E$ & \\
\hline \multicolumn{7}{|l|}{ DILS } \\
\hline$(n=10)$ & $370 \pm 37$ & 4.35 & $9 \pm 2$ & & $27 \pm 4$ & \\
\hline \multicolumn{7}{|l|}{$\mathrm{HIV}^{+}$} \\
\hline$(n=8)$ & $410 \pm 26$ & 2.27 & $36 \pm 5$ & 0.006 & $29 \pm 6$ & NS \\
\hline \multicolumn{7}{|l|}{ ARC } \\
\hline$(n=8)$ & $152 \pm 18$ & 2.31 & $39 \pm 8$ & 0.0082 & $45 \pm 6$ & NS \\
\hline \multicolumn{7}{|l|}{ AIDS } \\
\hline$(n=10)$ & $66 \pm 13$ & 1.82 & $36 \pm 6$ & 0.003 & $64 \pm 9$ & 0.021 \\
\hline \multicolumn{7}{|l|}{$\mathrm{HIV}^{-}$} \\
\hline$(n=9)$ & $792 \pm 62$ & 1.08 & $8 \pm 1$ & NS & $14 \pm 2$ & 0.011 \\
\hline
\end{tabular}

* Mann-Whitney two-tailed test comparison to individuals with DILS. 


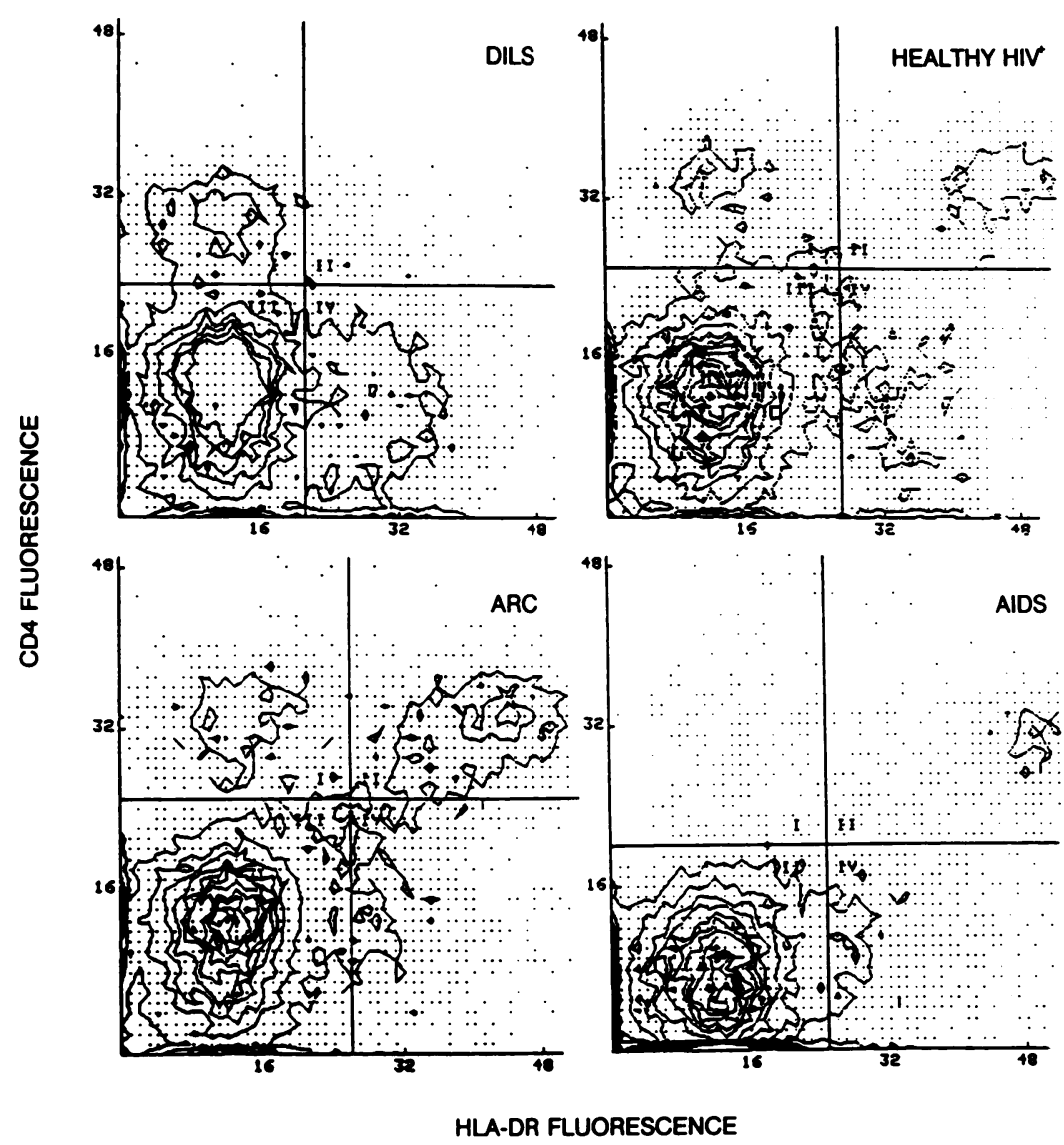

Figure 3. Two-color immunofluorescence analysis of circulating lymphocytes from four HIV-infected individuals stained with fluorescein- or biotin-conjugated CD4 or HLA-DR monoclonal antibodies, respectively, indicating the low level of CD4 T cell activation. While only $9 \%$ of the CD4 cells in the individual with DILS expressed HLA-DR molecules, the proportion of activated CD4 cells was $52 \%$ in the asymptomatic HIV-positive individual, $63 \%$ in the one with $\mathrm{ARC}$, and $74 \%$ in the individual with AIDS.
In another individual with DILS and biopsy-proven lymphocytic interstitial pneumonitis, $56 \%$ of the lymphocytes obtained by bronchoalveolar lavage were T cells, of which $>96 \%$ were $\mathrm{CD}^{+}$and bore $\alpha \beta$ T cell receptors. $73 \%$ of these cells expressed brightly CD29 and CD11a/CD18 structures, while only $10 \%$ were positive with CD45R mAbs. Only $11 \%$ of the CD8 cells in double label experiments were activated as defined by the presence of interleukin-2 receptors (CD25) and MHC class II molecules, data not illustrated.

\section{Discussion}

These studies suggest that both the circulating and infiltrative CD8 lymphocytosis in individuals with DILS are components of an antigenically driven, and immunogenetically determined, systemic host response to HIV-1 infection. These conclusions are based on the following major points: $(a)$ The expanded circulating lymphocyte population in persons with DILS primarily consisted of CD8 T cells with a memory phenotype, characterized by increased surface expression of CD1 1a/ CD18 (LFA-1), CD29 (very late arising-4 [VLA] $\beta_{1}$ chain), and, to a lesser extent, CD57 ( Leu 7) molecules. These cells did not express markers of recent activation such as interleukin-2 receptors or HLA-DR molecules. (b) The predominant lymphocytic population that infiltrated salivary, pulmonary, or renal tissues was accounted for by CD8 T cells with a similar memory phenotype to that found in the blood. (c) Strong expression of CD54 (ICAM-1) molecules was observed on postcapillary venule endothelium within the lymphoid aggregates, but not on endothelium at sites distant from the foci. This suggests that the entry of lymphocytes into tissues involves interactions between specific adhesion molecule receptor-ligand pairs such as LFA-1 / ICAM-1. (d) Expression of HIV-encoded proteins was demonstrable in salivary gland monocyte/macrophage lineage cells which were usually located in periacinar and perivascular locations in close proximity to lymphoid aggregates, and strongly expressed MHC class II molecules.

CD8 T cells bearing the same memory phenotype as identified in this report have been shown to suppress HIV-1 replication in humans by mechanisms requiring cell-cell interaction and MHC-restriction (27). Accordingly, it may be that individuals with DILS selectively expand a circulating population of CD8 T cells capable of suppressing HIV replication in vivo. In support of this possibility are the relatively preserved levels of CD4 T cells in this group, the low rate of progression to opportunistic infections (7), and the low expression of HIV-1 proteins in DILS peripheral blood, as determined by circulating p24 antigenemia (21). These observations imply that events in HIV-1 infection which normally result in CD4 T cell depletion and progression to opportunistic infections are attenuated or retarded in DILS. The low frequency of activated CD4 T cells in these individuals, as defined by surface expression of interleukin-2 receptors and MHC class II molecules, is of interest in view of the association between $\mathrm{T}$ cell activation and the transactivation of HIV-1 gene expression (28).

Because a substantial portion of the expanded CD8 population in patients with DILS expressed CD57 (Leu 7) molecules in addition to the $\beta$-integrins, this prominent cell type could be an important element of these individuals' cellular response to 

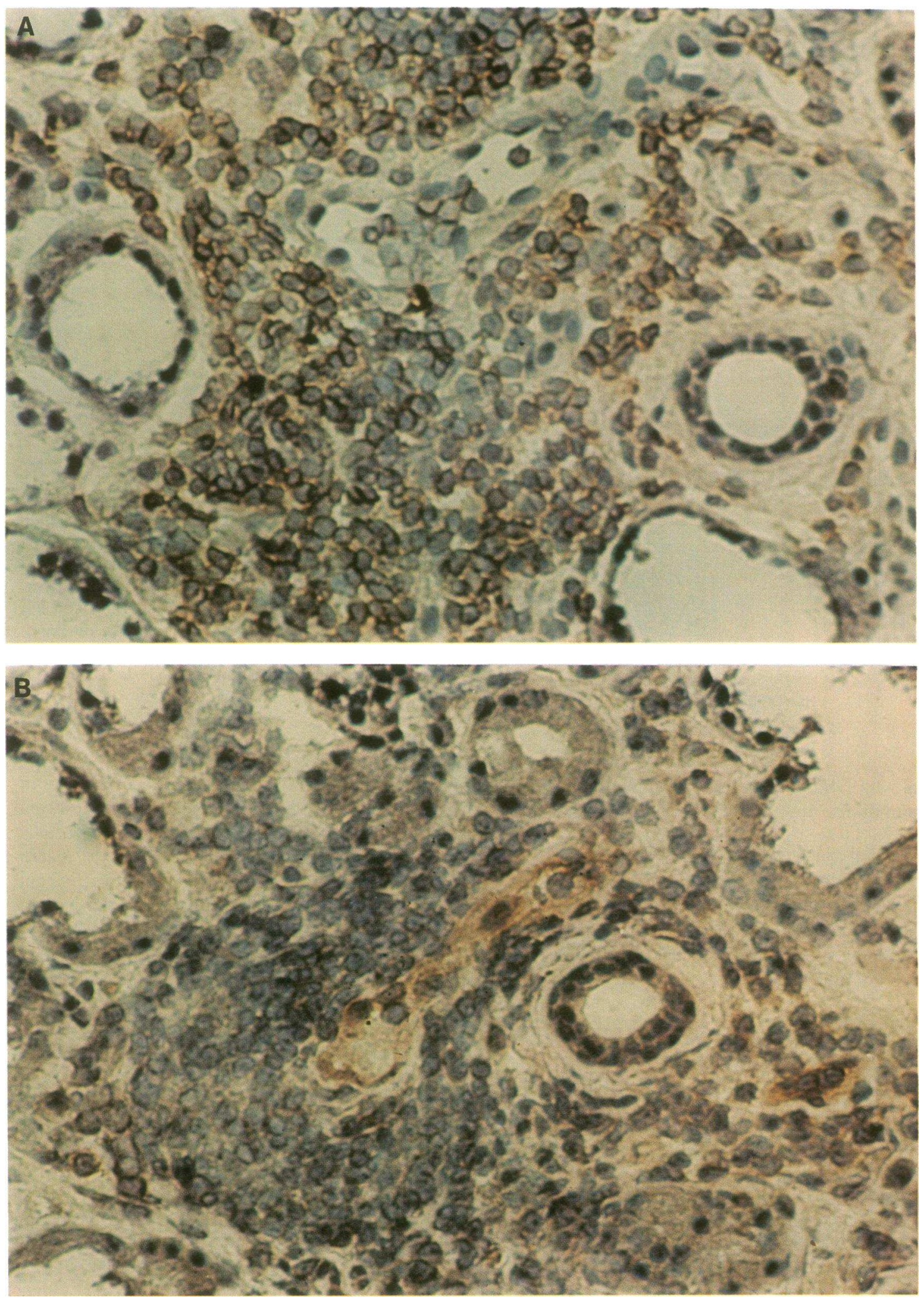

Figure 4. Immunohistochemical studies of minor salivary gland specimen from an HIV-infected individual with DILS demonstrating expression of the $\beta_{2}$-integrin CD1 1a/CD18 (LFA-1) by infiltrating lymphocytes $(A)$, CD54 (ICAM-1) expression by postcapillary venule endothelial cells within lymphoid focus $(B)$, and HLA-DR expression by acini, but not ducts $(C)$, in the vicinity of monocyte/macrophage lineage cells that also expressed HLA-DR $(C)$ and HIV-1 gp120 molecules $(D)$.

HIV. Increased numbers of $\mathrm{CD} 8{ }^{+} \mathrm{CD} 57^{+}$cells have previously been described in HIV-infected individuals at various stages of disease $(29,30)$, however their function remains unknown. In vitro, $\mathrm{CD} 8{ }^{+} \mathrm{CD} 7^{+}$cells have been demonstrated to be capable of suppressing pokeweed mitogen-induced $B$ cell antibody production (26), and of mediating lectin-induced cytotoxicity 

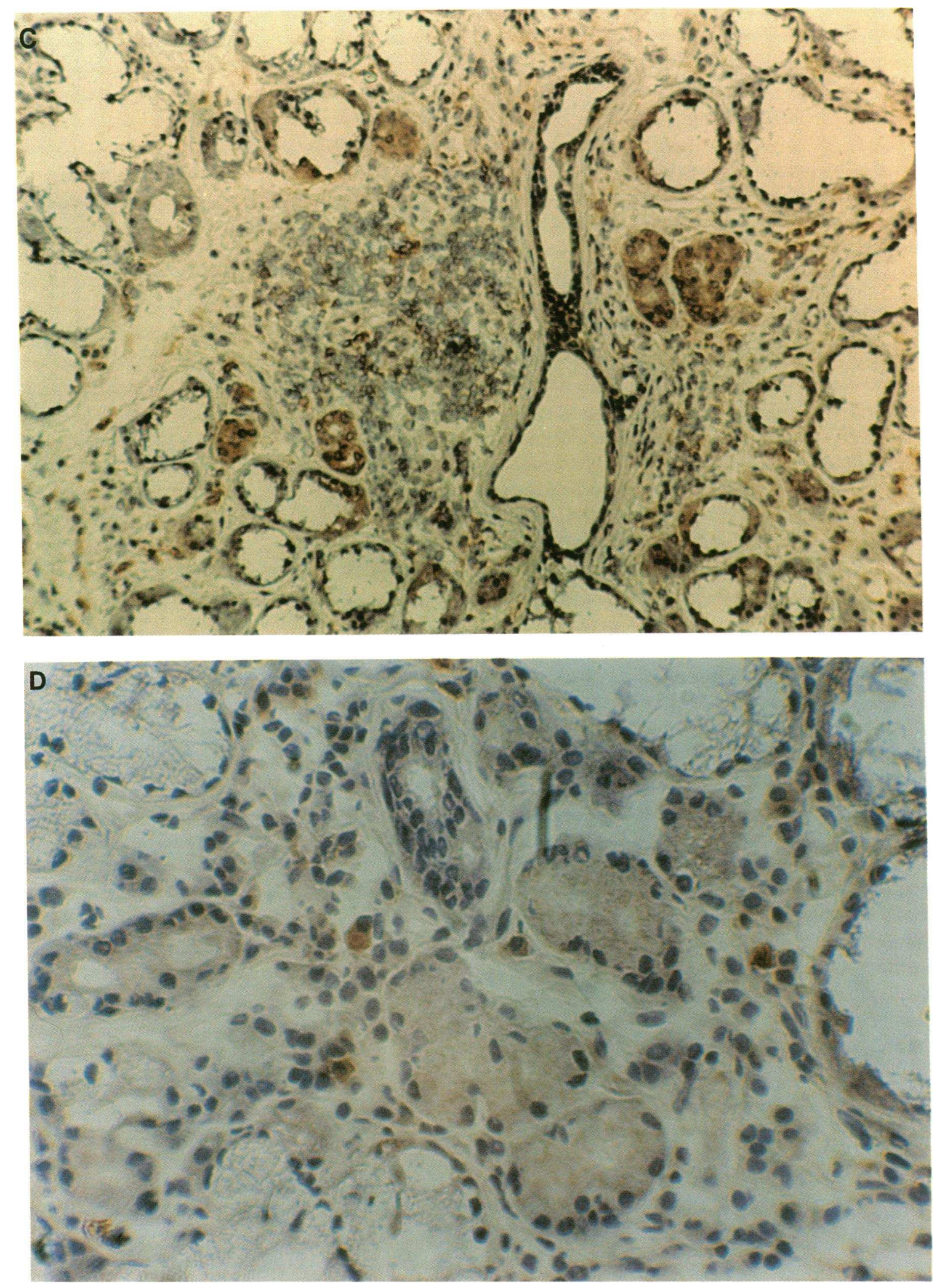

Figure 4 (Continued)

(31). Although CD57 is a marker present on certain NK cells, the $\mathrm{CD} 8{ }^{+} \mathrm{CD} 57^{+}$cells present in DILS patients are unlikely to be NK cells because they possess the $\mathrm{CD} 3 \mathrm{~T}$ cell receptor complex, lack other NK surface markers such as $\mathrm{CD} 16$ (Fc receptors) and CD1 lb/CD18 (CR3), and cells with this phenotype in other HIV-infected individuals have been shown to have little NK function (30).

In support of an antigen-driven basis to the CD8 lymphocytosis in DILS, analysis of the T cell receptor $\alpha$ and $\beta$ chain repertoire in lymphocytes infiltrating the minor salivary glands 
has revealed selective $\mathrm{V}$ and $\mathrm{J}$ gene segment usage and a preference for specific somatically encoded amino acid residues in the third complementarity determining region (32). These findings suggest that the infiltrative $T$ cell population is significantly restricted by virtue of antigen-driven clonal selection. While the exact nature of the inciting antigen in DILS remains to be determined, the present demonstration of HIV-1 proteins in salivary gland monocyte lineage cells, as well as the marked diminution in parotid gland enlargement and degree of lymphocytic tissue infiltration after therapy with the reverse transcriptase antagonist zidovudine, likely implicates HIV-1 as the causal agent. However, we cannot exclude the less likely possibilities that the infiltrating lymphocytes may alternatively be reacting to endogenous or exogenous structures whose expression is regulated by the local presence of HIV-1, or even to other retroviruses present at these sites.

The results presented in this report suggest the following hypothetical model for the HIV-host interactions occurring in DILS. Monocytes infected with HIV-1 leave the circulation and localize at various mucosal sites where they differentiate into resident tissue macrophages and induce clinical complications such as lymphocytic interstitial pneumonitis or central nervous system disease (33). The anatomic localization of these monocytes to salivary and pulmonary tissues, gastrointestinal tract, and renal tubules, which occurs for unknown reasons, may account for the particular pattern of organ involvement that is characteristic of DILS. Viral persistence in these cells is associated with the secretion of a number of cytokines, including TNF- $\alpha$, which is a very potent inducer of ICAM-1 expression on endothelial cells $(11,14)$. Alone or in combination with other cytokines, TNF- $\alpha$ may induce the enhanced local expression of adhesion molecule ligands by postcapillary venule endothelium in the salivary glands and other tissues.

In those immunogenetically distinct individuals who are capable of responding to HIV-1 infection by developing a reactive circulating CD8 lymphocytosis, memory CD8 T cells are first primed by exposure to HIV-1 within lymphatic tissues. These lymphocytes express selective homing receptors and are sequestered into salivary glands, lungs, and other organs by interactions between accessory molecules on lymphocytes such as the integrins and those on endothelial cells such as ICAM-1. It is possible that immune recognition events occurring between TCR structures on these memory CD8 T cells and HIV peptide/MHC complexes on the tissue macrophages may lead, by as yet undefined mechanisms, to the suppression of HIV-1 replication in the infected cells. The elaboration of cytokines such as $\gamma$-interferon during this immune interaction would, in conjunction with factors released by the infected macrophages, lead to additional secondary parenchymal damage.

Similar mechanisms to those occurring in HIV-1 infection, involving abnormal tissue expression of adhesion molecules, may be responsible for the tissue infiltration and damage that occur in other disorders associated with the sicca syndrome, including HTLV-1 infection, chronic graft-versus-host disease, and idiopathic Sjögren's syndrome. Although each of these disorders differs from DILS and from each other in many respects, the present results suggest that the characteristic pattern of $T$ cell recruitment into the same organs in each disorder may reflect a common final pathway. A further factor contributing to the tissue specificity of the infiltrative process in these disorders might be the presence of regulatory cofactors at involved sites. In DILS, for example, HIV-1 replication in salivary tis- sues may be enhanced by human herpes virus 6 and epidermal growth factor, two cofactors that are principally located in the salivary glands $(34,35)$, and that are, respectively, capable of transactivating HIV-1 (36) and increasing HIV-1 replication in infected cell lines (37).

\section{Acknowledgments}

We thank Ms. Modrie Payne and Ms. Lillian Richman for excellent assistance in the preparation of this manuscript.

This work was supported in part by National Institutes of Health grant AR39626. S. Itescu is a postdoctoral Fellow of the Arthritis Foundation.

\section{References}

1. Lane, H. C., and A. S. Fauci. 1985. Immunologic abnormalities in the acquired immune deficiency syndrome. Annu. Rev. Immunol. 3:477.

2. Walker, B. D., S. Chakrabarti, B. Moss, T. J. Paradis, T. Flynn, A. G. Durno, R. S. Blumberg, J. C. Kaplan, M. S. Hirsch, and R. T. Schooley. 1987. HIV-specific cytotoxic $\mathrm{T}$ lymphocytes in seropositive individuals. Nature (Lond.). 328:345-348.

3. Walker, C. M., D. J. Moody, D. P. Stites, and J. A. Levy. 1986. CD8 ${ }^{+}$ lymphocytes can control HIV infection in vitro by suppressing viral replication. Science (Wash. DC). 234:1563-1566.

4. Siliciano, R. F., T. Lawton, C. Knall, et al. 1988. Analysis of host-virus interactions in AIDS with anti-gp $120 \mathrm{~T}$ cell clones: effect of HIV sequence variation and a mechanism for CD4 ${ }^{+}$cell depletion. Cell. 54:561-575.

5. Zolla-Pazner, S., D. C. Des Jarlais, S. R. Friedman, et al. 1987. Nonrandom development of immunologic abnormalities after infection with human immunodeficiency virus: implications for immunologic classification of the disease. Proc. Natl. Acad. Sci. USA. 84:5404-5408.

6. Itescu, S., L. J. Brancato, and R. Winchester. 1989. A sicca syndrome in HIV infection: association with HLA-DR5 and CD8 lymphocytosis. Lancet. ii:466-468.

7. Itescu, S., U. Mathur-Wagh, M. L. Skovron, L. J. Brancato, M. Marmor, A. Zeleniuch-Jacquotte, and R. Winchester. 1992. HLA-B35 is associated with accelerated progression to AIDS. J. AIDS. 5:37-45.

8. Itescu, S., L. J. Brancato, E. Dwyer, P. K. Gregersen, and R. Winchester. 1990. Susceptibility to HIV-associated Sjogren's syndrome requires interaction of MHC class I and II gene products. Arthritis Rheum. 33(Suppl.):S79. (Abstr.)

9. Meiser, S. C., S. F. Schlossman, and E. L. Reinhertz. 1982. Clonal analysis of human cytotoxic $\mathrm{T}$ lymphocytes: T4+ and T8+ effector cells recognize products of different major histocompatibility complex regions. Proc. Natl. Acad. Sci. USA. 79:4395.

10. Martz, E. 1986. LFA-1 and other accessory molecules functioning in adhesions of $\mathrm{T}$ and $\mathrm{B}$ lymphocytes. Hum. Immunol. 18:3-37.

11. Springer, T. A., M. L. Dustin, T. K. Kishimoto, and S. D. Marlin. 1987. The lymphocyte function-associated LFA-1, CD2, and LFA-3 molecules: cell adhesion receptors of the immune system. Annu. Rev. Immunol. 5:223-252.

12. Vollger, L. W., D. T. Tuck, T. A. Springer, B. F. Haynes, and K. H. Singer. 1987. Thymocyte binding to human thymic epithelial cells is inhibited by monoclonal antibodies to CD-2 and LFA-3 antigens. J. Immunol. 138:358.

13. Jalkanen, S., R. A. Reichert, W. M. Gallatin, R. F. Bargatze, I. L. Weissman, and E. C. Butcher. 1986. Homing receptors and the control of lymphocyte migration. Immunol. Rev. 91:39.

14. Springer, T. A. 1990. Adhesion receptors of the immune system. Nature (Lond.). 346:425-434.

15. Hogg, N. 1989. The leukocyte integrins. Immunol. Today. 10:111-114.

16. Smith, S. H., M. H. Brown, D. Rowe, R. E. Callard, and P. C. Beverley. 1986. Functional subsets of human helper-inducer cells defined by a new monoclonal antibody. UCHL1. Immunology. 58:63.

17. Sanders, M. E., M. W. Makgoba, S. O. Sharrow, D. Stephany, T. A. Springer, H. A. Young, and S. Shaw. 1988. Human memory T lymphocytes express increased levels of three cell adhesion molecules (LFA-3, CD2, and LFA1 ) and three other molecules (UCHL1, CDw29, and Pgp-1) and have enhanced IFN-gamma production. J. Immunol. 140:1401-1407.

18. Morimoto, C., N. L. Letvin, A. W. Boyd, M. Hagan, and H. M. Brown 1985. The isolation and characterization of the human helper inducer $T$ cell subset. J. Immunol. 134:3762.

19. Budd, R. C., J. C. Cerottini, and H. R. MacDonald. 1987. Selectively increased production of interferon-gamma by subsets of Lyt-2 cells. J. Immunol. 138:1009.

20. Haverkos, H. W., M. S. Gotlieb, J. Y. Killen, et al. 1985. Classification of HTLV-III/LAV-related diseases. J. Infect. Dis. 152:1095. 
21. Itescu, S., L. J. Brancato, J. Buxbaum, P. K. Gregersen, C. C. Rizk, S. Croxson, G. Solomon, and R. Winchester. 1990. A diffuse infiltrative CD8 lymphocytosis syndrome in human immunodeficiency virus (HIV) infection: a host immune response associated with HLA-DR5. Ann. Intern. Med. 112:3-10.

22. Winchester, R. J. and G. D. Ross. 1985. Methods for enumerating cell population by surface markers using conventional microscopy. In Manual of Clinical Laboratory Immunology. N. Rose and H. Friedman, editors. American Society for Microbiology, Washington, DC. 212-225.

23. Chisholm, D. M., and D. K. Mason. 1968. Labial salivary gland biopsy in Sjögren's disease. J. Clin. Pathol. (Lond.). 21:656.

24. Adamson, T. C., III, R. Fox, D. M. Frisman, and F. V. Howell. 1983. Immunohistologic analysis of lymphoid infiltrates in primary Sjögren's syndrome using monoclonal antibodies. J. Immunol. 130:203-208.

25. Celada, F., C. Cambiaggi, J. Maccari, S. Burastero, T. Gregory, E. Patzer, J. Porter, C. McDanal, and T. Matthews. 1990. Antibody raised against soluble CD4-rgp 120 complex recognizes the CD4 moiety and blocks membrane fusion without inhibiting CD4- gp120 binding. J. Exp. Med. 172:1143-1150.

26. Clement, L. T., C. E. Grossi, and G. L. Gartland. 1984. Morphologic and phenotypic features of the subpopulation of Leu- $2+$ cells that suppresses B cell differentiation. J. Immunol. 133:2461-2468.

27. Tsubota, H., C. I. Lord, D. I. Watkins, C. Morimoto, and N. L. Letvin. 1989. A cytotoxic T lymphocyte inhibits acquired immunodeficiency syndrome virus replication in peripheral blood lymphocytes. J. Exp. Med. 169:1421-1434.

28. Siekevitz, M., S. F. Josephs, M. Dukovich, N. Peffer, F. Wong-Staal, and W. C. Green. 1987. Activation of the HIV-1 LTR by T-cell mitogens and the trans-activator protein of HTLV-1. Science (Wash. DC). 238:1575-1578.

29. Lewis, D. E., J. M. Puck, G. F. Babcock, and R. R. Rich. 1985. Dispropor- tionate expansion of a minor $\mathrm{T}$ cell subset in patients with lymphadenopathy syndrome and acquired immunodeficiency syndrome. J. Infect. Dis. 151:555559.

30. Plaeger, M. S., C. A. Spina, J. V. Giorgi, R. Mitsuyasu, P. Wolfe, M. Gottlieb, and G. Beall. 1987. Alterations in cytotoxic and phenotypic subsets of natural killer cells in acquired immune deficiency syndrome (AIDS). J. Clin. Immunol. 7:16-23.

31. Phillips, J. H., and L. L. Lanier. 1986. Lectin-dependent and anti-CD3 induced cytotoxicity are preferentially mediated by peripheral blood cytotoxic $\mathrm{T}$ lymphocytes expressing Leu-7 antigen. J. Immunol. 136:1579-1585.

32. Dwyer, E., S. Itescu, and R. Winchester. 1991. Selective $\alpha \beta$ T cell receptor usage in diffuse infiltrative lymphocytosis syndrome. Clin. Res. 39:255 A. (Abstr.)

33. Meltzer, M. S., D. R. Skillman, P. J. Gomatos, D. C. Kalter, and H. E. Gendelman. 1990. Role of mononuclear phagocytes in the pathogenesis of HIV infection. Annu. Rev. Immunol. 8:169-194.

34. Fox, J. D., M. Briggs, P. A. Ward, and R. S. Tedder. 1990. Human herpesvirus 6 in salivary glands. Lancet. 336:590-593.

35. Thesleff, I., L. Viinikka, L. Saxen, E. Lehtonen, and J. Perheentupa. 1988. The parotid gland is the main source of human salivary epidermal growth factor. Life Sci. 43:13-18.

36. Ensoli, B., P. Lusso, F. Schachter, S. F. Josephs, J. Rappaport, F. Negro, R. C. Gallo, and F. Wong Staal. 1989. Human herpes virus-6 increases HIV-1 expression in co-infected T cells via nuclear factors binding to the HIV-1 enhancer. EMBO (Eur. Mol. Biol. Organ.) J. 8:3019-3027.

37. Berkower, I., G. E. Smith, C. Giri, and D. Murphy. 1989. Human immunodeficiency virus 1 . Predominance of a group-specific neutralizing epitope that persists despite genetic variation. J. Exp. Med. 170:1681-1695. 